\title{
Da Crise Financeira à Crise da Dívida Soberana: Um Debate sobre a Política Fiscal
}

\section{From the Financial Crisis to the Sovereign Debt Crisis: a Debate on Fiscal Policy}

Celso Pereira Neris Junior* Mário Augusto Bertella**

Resumo: A crise financeira de 2007 trouxe à tona a discussão sobre a política fiscal. Esta foi empregada como forma dos governos atenuarem os impactos econômicos e sociais potenciais da crise, uma vez que apenas o expediente monetário não daria conta do processo. Historicamente, crises bancárias engendram aumentos das dívidas públicas, não somente pelas operações de socorro, mas também pelas políticas de gasto primário dos governos e/ou, como na crise recente, pela compra de ativos financeiros "tóxicos". A discricionariedade da política fiscal é colocada em discussão, uma vez que, sendo ela imprescindível, requerem-se ações coordenadas e bem articuladas para que os países consigam mitigar suas respectivas crises atuais e futuras.

Palavras-chave: Crise financeira. Crise da dívida. Política fiscal.

Abstract: The financial crisis of 2007 brought the discussion of fiscal policy. This was used as a way for governments to mitigate the potential social and economic impacts of the crisis, since only the monetary policy would not be effective. Historically, banking crises engender increases in public debt, not only for the relief operations, but also by the policies of government primary spending and/or, as in the recent crises, by the purchase of the "toxic" financial assets. The discretionary fiscal policy is then discussed, since it is essential, it is required well articulated and coordinated actions in order to mitigate their respective current and future crisis.

Keywords: Financial crisis. Debt crisis. Fiscal policy.

JEL Classification: E61; E62; G01; H63.

Aluno do Doutorado em Ciências Econômicas no Instituto de Economia da Universidade Estadual de Campinas (IE/Unicamp).E-mail: cnerisjr@yahoo.com.br

* $\quad$ Professor doutor do Departamento de Economia da Faculdade de Filosofia, Ciências e Letras de Araraquara (FCLAR/Unesp). E-mail: mabertella@yahoo.com.br 


\section{1 lntrodução}

Os formuladores de políticas ao redor do mundo usaram estímulos fiscais para atenuar as perturbações econômicas e sociais advindas da crise financeira de 2007. Houve certo consenso de que o setor bancário necessitaria ser salvo para evitar uma crise sistêmica e restaurar a confiança da economia. Medidas fiscais de curto prazo foram tomadas para estimular a economia e referendadas por diversos economistas, incluindo organizações governamentais e governos, até então reticentes a esses estímulos.

A crise, porém, potencializou os problemas de economias já endividadas e com problemas de solvência que tiveram de usar esses expedientes, agravando ainda mais sua posição fiscal e dando início a um temor irrepreensivel de contágio. Casos evidentes são os da Grécia, Irlanda, Portugal, Itália e Espanha, que impuseram um impasse recente à zona do euro e cujo desdobramento está longe de ser conhecido.

Os problemas relacionados às dívidas, logo após as crises bancárias, tiveram destaque especial no recente estudo de Reinhart e Rogoff (2010). Os autores chegaram ao resultado de que, em média, a dívida pública aumenta cerca de $86 \%$ nos três anos seguintes à uma crise financeira. Isso não só por conta das operações de socorro aos bancos, mas também por conta do emprego da política fiscal a fim de manter o nível de emprego e renda em suas economias.

Este artigo procura mostrar o circuito que levou à recente crise da dívida soberana vivida pelos países europeus, a saber, dívida privada que originou uma crise bancária, chegando aos problemas da dívida soberana vividos pela zona do euro, potencializado pelas dívidas já existentes e pelas incertezas dos investidores. Procuramos ficar somente nos aspectos fiscais para que possamos discutir a contribuição dessas políticas à recente crise. Para isso, dividimos o artigo em quatro seções, além desta introdução. Na primeira, buscamos contextualizar a crise financeira recente através de um breve histórico. Na segunda, apresentamos uma discussão sobre o papel da política fiscal. Na terceira seção mostramos a tendência histórica dos desdobramentos de uma crise financeira e a situação fiscal de países como Grécia e Irlanda. Na quarta seção apresentamos uma discussão sobre a responsabilidade da política fiscal na crise atual da zona do euro e quais deveriam ser os seus ajustes a fim de evitar um colapso maior. Por fim, tecemos algumas considerações finais.

\section{Breve Histórico da Crise de 2007}

A crise financeira de 2007 teve como epicentro o mercado de hipotecas nos Estados Unidos, sendo considerada a maior crise financeira pela qual já passou a 
economia mundial desde a crise de 1929. Não por acaso, Reinhart e Rogoff (2010) designam a crise iniciada em 2007 como a "segunda grande contração". Segundo o relatório Bank for International Settlements - BIS (2009), essa crise pode ser dividida em cinco etapas. A primeira ocorreu entre junho de 2007 e meados de março de 2008, quando surgem os problemas relativos às hipotecas sub-prime; em seguida, veio a percepção das dificuldades nesse mercado e o aumento da sensação de insolvência; a terceira tem como marco a falência do Lehman Brothers no dia 15 de setembro de 2008; essa etapa deu início a um pânico que se abateu sobre a economia mundial, ocorrido entre outubro de 2008 e meados de março de 2009, figurando a quarta etapa. Por fim, a última fase surge após março de 2009, quando aparece certo otimismo de governos e mercados, a despeito dos indicadores macroeconômicos estarem aquém da normalidade (BIS, 2009).

Essas fases tiveram eventos marcantes que desencadearam a sensação de que a crise já não era somente concentrada nos Estados Unidos. Na primeira etapa, houve a aquisição do banco de investimentos Bear Sterns, em março de 2008, por J. P Morgan Chase, no valor de 29 bilhões de dólares. De um problema de liquidez dentro do sistema financeiro, a economia passou a encarar como o maior problema de curto prazo a solvência de algumas instituições. Concomitantemente à piora na percepção pelos investidores da situação dos bancos, as agências norte-americanas Fannie Mae e Freddie Mac apresentaram perdas trimestrais bem acima das previsões do mercado. O governo dos Estados Unidos adquiriu formalmente, em setembro de 2008, essas duas agências pelo valor de 200 bilhões de dólares. Outras instituições também contaram com o auxílio do governo a fim de evitar a bancarrota, como foram os casos da Goldman Sachs e da Morgan Stanley. Em 17 de setembro de 2008, a AIG, uma das maiores seguradoras do mundo, foi estatizada pelo valor inicial de 85 bilhões de dólares, em seguida os pacotes de resgate alocaram cerca de 182 bilhões de dólares, tornando o maior empréstimo ocorrido nos Estados Unidos. Nos países europeus e nos Estados Unidos, seguiu-se uma onda de intervenções de socorro até o final de setembro, com nova rodada em outubro, além da tentativa de ações coordenadas entre bancos centrais dos Estados Unidos e da Europa (BIS, 2009).

Mishkin (2010) divide a crise financeira de 2007-2009 em duas fases. A primeira é relativamente mais limitada e afeta um segmento relativamente pequeno do sistema financeiro dos Estados Unidos, que vai de agosto de 2007 a agosto de 2008. Nessa fase, o PIB do país continuou a subir até o segundo trimestre de 2008, o que levava a crer que a recessão teria apenas um impacto moderado sobre a economia do país. Em meados de setembro de 2008, a crise entrou em uma fase muito mais virulenta, iniciando-se com a quebra do banco de investimentos Lehman Brothers. No mesmo mês, a empresa de seguros AIG também faliu, dando-se, então, uma corrida para salvar o sistema financeiro através do Programa de Alívio de Ativos Problemáticos (Troubled Asset Relief Plan - TARP). 
O autor mostra que uma crise financeira se transforma em uma crise global por conta de três motivos. Primeiro, a crise aumenta os spreads de crédito correspondentes à diferença entre a taxa de juros dos títulos públicos e os títulos Baa corporate, debilitando a política monetária, pois as taxas de juros que deveriam ser cortadas para estimular a economia, através da demanda agregada, ficam impedidas de sofrer quedas, uma vez que os bancos elevam seus spreads. Segundo, o declínio dos preços dos ativos durante uma crise financeira provoca uma queda no valor dos colaterais, o que torna mais difícil para as empresas não financeiras tomar emprestado. Além disso, a deterioração dos balanços das empresas financeiras, que têm o conhecimento necessário para mitigar problemas de seleção e risco moral, provoca uma redução no volume de empréstimos ofertados. Terceiro, o aumento geral da incerteza que ocorre durante uma crise financeira também leva a um aumento da assimetria de informação, dificultando ainda mais a capacidade dos mercados financeiros em alocar fundos para as famílias e empresas (MISHKIN, 2010).

Segundo Bresser-Pereira (2009), a crise financeira ocorreu no epicentro do capitalismo, nos Estados Unidos, legitimador de uma teoria econômica que se baseia nos pressupostos de "expectativas racionais" e "escolhas racionais", dando suporte à tese de sistemas financeiros desregulados. Tal teoria, segundo ele, não foi a utilizada pelos formuladores de política econômica nos governos, senão a de linha keynesiana (HERMAN, 2009). Assim, o Estado surgiu como a única tábua de salvação em cada país. A partir das medidas de natureza fiscal e monetária postas em prática pelos Estados Unidos, pelos países da zona do euro e pelo Japão para evitar uma recessão econômica mais aguda - medidas essas como injeção de liquidez e de capital nos sistemas financeiros e a redução sincronizada da taxa básica de juros dos principais bancos centrais mundiais -, a crise nos levou a repensar o papel do Estado na economia, tornando a ação estatal fundamental para prevenir ou remediar a crise - remetendo à ideia de Minsky, na qual a crise deve ser enfrentada pela ação de um banco central como emprestador de última instância e de uma política fiscal anticíclica, além de uma maior coordenação global entre as diferentes políticas nacionais, em particular dos países desenvolvidos (FERRARI FILHO; PAULA, 2009).

Ainda, alguns autores interpretaram a crise como decorrência da falta de regulamentação sobre as superinstituições financeiras (FARHI et al., 2009) e por conta do atual arcabouço regulatório (MENDONÇA, 2009). Além disso, deu-se em decorrência da falta de políticas públicas habitacionais para os "subcidadãos", evidenciando a falta da atuação do Estado e não a sua ativa ação como causadora da crise (SICSÚ, 2009). Sendo assim, prevenir-se de crises sistêmicas futuras não pode prescindir de mudanças na governança do sistema financeiro internacional. Seria necessário, entre outras ações, consolidar as diversas agências regulatórias europeias e norte-americanas, uma vez que a crise revelou a obsolescência da 
estrutura de supervisão descentralizada, dado o elevado grau de imbricação entre as diversas instituições e mercados. Também, deveriam ser impostos limites ao avanço da securitização e dos derivativos de crédito, que foram responsáveis pelo crescente default dos empréstimos das hipotecas subprime nos Estados Unidos (FARHI et al., 2009).

A recuperação pós-crise ocorreu em grande parte por conta de políticas fiscais expansionistas, políticas monetárias de sustentação de liquidez e políticas macroeconômicas de incentivo a setores específicos, como as aplicadas na indústria automobilística e de construção civil, que reativaram a demanda agregada e mitigaram o impacto das tendências naturais dos agentes econômicos de se retraírem frente ao desemprego, às incertezas e ao excesso de endividamento de alguns setores (CARVALHO, 2011). Não passou despercebido, porém, o fato de que a despeito dos sinais de recuperação que a economia mundial oferecia no final de 2010 e início de 2011, países da zona do euro apresentavam sérias instabilidades em seus sistemas financeiros, sobretudo por conta da crise fiscal dos então chamados PIIGS (Portugal, Itália, Irlanda, Grécia e Espanha) (PAULA; FERRARI FILHO, 2011; CARVALHO, 2011). Isso evidenciou a ausência de descolamento não só em países emergentes (PRATES, 2011), para os quais se voltava a atenção no período. Havia um temor em relação aos déficits públicos e o crescimento da dívida pública interna dos PIIGS como novo fator de desequilíbrio da economia mundial, uma vez que esses países possuíam traços comuns, como um problema crônico de ausência de competitividade externa, refletido em grandes déficits em conta corrente, somados a seus desequilíbrios fiscais (OREIRO, 2011).

\section{A Discussão da Política Fiscal como Resposta à Crise}

Como já ressaltado, uma das principais respostas à crise foram os estímulos fiscais dados por alguns países. A administração Obama, através do American Recovery and Reinvestment Act, de 2009, injetou 787 bilhões de dólares na economia. Assim dividido, o plano apresentado previa 288 bilhões de dólares em cortes de impostos e US $\$ 499$ bilhões com gastos do governo (MISHKIN, 2010). Em todo o mundo, outros países também afetados pela grande recessão que se iniciava passaram a adotar estímulos fiscais. Holland e Mori (2010), em uma análise das políticas de resposta à crise de 2007, afirmaram que, no Brasil, além das ações relativas ao sistema financeiro ${ }^{1}$, focadas em um primeiro momento em preservar

$1 \quad$ Como medidas especiais para estabilizar o sistema financeiro, os autores listam seguros de depósito, restrições em short selling positions, injeções de capital, garantias de dívidas, seguro de ativos, compra de ativos e nacionalização. No Brasil, as ações do Banco Central focaram-se, nos meses finais de 2008, na liberação de compulsórios e garantias para que o sistema mantivesse um ritmo operacional adequado, de forma que, como medida especial, só dispôs do expediente de injeções de capital (HOLLAND; MORI, 2010). 
sua solidez ante a contração do crédito global em curso no último trimestre de 2008, no plano fiscal, as medidas adotadas que se revelaram mais efetivas foram as reduções de tributos específicos e os incentivos dados para determinados setores (automotivo, bens duráveis e construção civil) que possuíam maior sensibilidade ao crédito.

Para Auerbach et al. (2010), a prevalência de intervenções de políticas fiscais no período se deveu tanto à severidade da recessão quanto a um otimismo revelado no que diz respeito ao potencial da eficácia da política fiscal. No entanto, o autor afirma que a variedade de políticas adotadas também sugere incerteza sobre quais abordagens poderiam ser mais eficazes.

Segundo Alesina e Ardagna (2009), após o período de grande redução dos déficits orçamentais dos anos 1990 e início do novo século, as finanças públicas dos países da OCDE voltaram ao vermelho. Há poucos meses, antes da crise de 2007, a principal discussão era se o corte de impostos ou aumento dos gastos seria a melhor receita para o plano de estímulos dos Estados Unidos e de outros países; no período atual, porém, essas decisões já foram tomadas e agora se avaliam os resultados. Para os autores, o desafio seguinte dos governos é pensar em como fazer para que o crescimento da dívida pública cesse e volte ao seu nível normal. Apesar de mostrarem evidências históricas ${ }^{2}$ de que grandes dívidas foram cortadas de forma relativamente rápida, sustentadas pelo crescimento econômico, quando, sem praticamente qualquer aumento de impostos ou corte de gastos significativos, grandes déficits transformaram-se em superávits expressivos. ${ }^{3}$ Sobre isso, os autores argumentam que seria otimista demais esperar que isso acontecesse novamente, uma vez que um cenário de menor crescimento econômico nos próximos anos será o mais provável.

Reinhart e Sbrancia (2011) argumentam que, em particular, a dívida pública em relação ao PIB é um índice que raramente é reduzido através de um robusto e consistente crescimento econômico, o que o coloca em confronto com Alesina e Ardagna (2009). Para os primeiros, mais comumente, a redução significativa dos níveis de dívida tem sido resultado de austeridade fiscal, reestruturação da dívida (default, por vezes definitiva) ou uma combinação destas.

Ainda sobre as questões de política fiscal, Auerbach et al.(2010) apresentam uma discussão sobre o ensino da macroeconomia. Até muito recentemente, um aluno de macroeconomia entraria em contato com um grupo de argumentos bem ensaiados sobre as tentativas de ajustes fiscais nas décadas anteriores. Ele aprenderia que a incerteza sobre os multiplicadores da política fiscal implicaria uma

2 Como são os casos das dívidas pós Segunda Guerra Mundial dos países beligerantes e dos Estados Unidos, na década de 1990.

3 No Reino Unido, a dívida sobre o PIB no final da Segunda Guerra Mundial foi mais de 200\%, mas o país não sofreu uma crise financeira devido a sua posição fiscal historicamente crível. 
desejável intervenção fraca (BRAINARD, 1967) e que a crítica de Lucas (1976) implica que os efeitos de uma política de estabilização podem ser minados por expectativas e ações de agentes racionais que observam o processo de políticas governamentais. Além disso, aprenderia a noção de equivalência ricardiana, que mostra ceticismo acerca da eficácia da política fiscal. Finalmente, o estudante seria lembrado das ferramentas alternativas de política de estabilização, como as intervenções dos bancos centrais independentes na taxa de juros e os estabilizadores automáticos já incorporados pelos governos, bem como o sistema de transferências. Esses argumentos contrários à política fiscal vieram à tona com a crise e não tardou que alguns autores se opusessem à teoria keynesiana de combate à recessão.

Em uma perspectiva pós-keynesiana, Arestis e Sawyer (2010) defendem que a política fiscal é um instrumento mais eficaz do que a política monetária e que os argumentos de que a primeira é impotente não são válidos. Para eles, recentemente houve uma mudança de atitude em relação à política fiscal, uma vez que, nas últimas décadas, a sabedoria convencional tem se pautado pelas seguintes proposições:

a) a política monetária é o principal instrumento para a gestão macroeconômica (geralmente orientada a controlar a inflação) e a política fiscal tem um papel de apoio ou coadjuvante para amortecer oscilações na atividade econômica, o que se reflete no novo consenso da macroeconomia;

b) a noção de equivalência ricardiana limita o uso da política fiscal, pois o déficit orçamentário é impotente para afetar o nível de atividade econômica, uma vez que seus efeitos sobre a demanda agregada decorrentes de aumentos na despesa pública seriam anulados por reduções no presente na demanda privada, dado o aumento da dívida pública no futuro;

c) por fim, ganhou força o argumento da prodigalidade em que o uso da política fiscal acabaria por produzir déficit orçamentário que levaria a uma dívida pública insustentável; por isso, variantes de regras de equilíbrio orçamentário foram defendidas. Um exemplo claro disso é o Pacto de Estabilidade e Crescimento da União Europeia (área do euro), no qual o déficit público máximo permitido seria de $3 \%$ sobre o PIB e uma dívida pública de $60 \%$ também como proporção do produto.

Nesse sentido, argumentam os autores que as respostas em termos de política fiscal para a crise financeira foram notáveis em dois aspectos. Em um primeiro momento, não houve tentativa para equilibrar o orçamento, reduzir despesas ou 
aumentar impostos ${ }^{4}$. Em segundo lugar, houve uma brusca mudança de atitude para com o uso da política fiscal discricionária e aumentos no déficit orçamentário, embora estes já estivessem subindo pelos efeitos da recessão. No entanto, depois destas considerações, é ainda duvidoso que tenha ocorrido uma mudança de paradigma acerca da política fiscal, pois é de se esperar que essa atitude tenha sido apenas temporária, dada a ineficácia da política monetária nessa situação.

\section{Dívida Pregressa e Adquirida: Elementos para uma Nova Crise}

\subsection{A Dívida Pública em Perspectiva Histórica}

A Figura 1 mostra os picos de endividamentos estudados por Reinhart e Rogoff (2010) e as soluções encontradas. Nos últimos anos, a dívida pública nas economias avançadas subiu para níveis que não foram registrados desde o fim da Segunda Guerra Mundial. Até 2010, a relação dívida/PIB para todas as economias avançadas já havia ultrapassado os picos alcançados durante a Primeira Guerra Mundial e, posteriormente, durante a Grande Depressão. Níveis de dívida privada, particularmente de instituições financeiras e famílias, estavam similarmente em territórios desconhecidos. Ao longo dos tempos e em todos os continentes, a guerra tem sido uma força causal recorrente por trás da rápida deterioração das finanças públicas e picos de endividamento público. Em tempos de paz, um dos principais fatores por trás dos surtos de dívida pública são as crises financeiras sistêmicas. Com a crescente tendência do governo de se estender em operações de socorro, a ligação entre dívida financeira e pública tornou-se mais pronunciada nas últimas duas décadas ou mais (REINHART; SBRANCIA, 2011; REINHART; ROGOFF, 2010).

4 Dizemos num primeiro momento, porque no instante em que escrevemos este artigo (fevereiro de 2012), alguns países europeus têm trilhado o caminho de redução de despesas e aumento de receitas públicas, como Portugal, Grécia, Espanha e Itália. 
Figura 1 - Surgimento da dívida pública e sua resolução: economias avançadas e mercados emergentes (1900-2011)

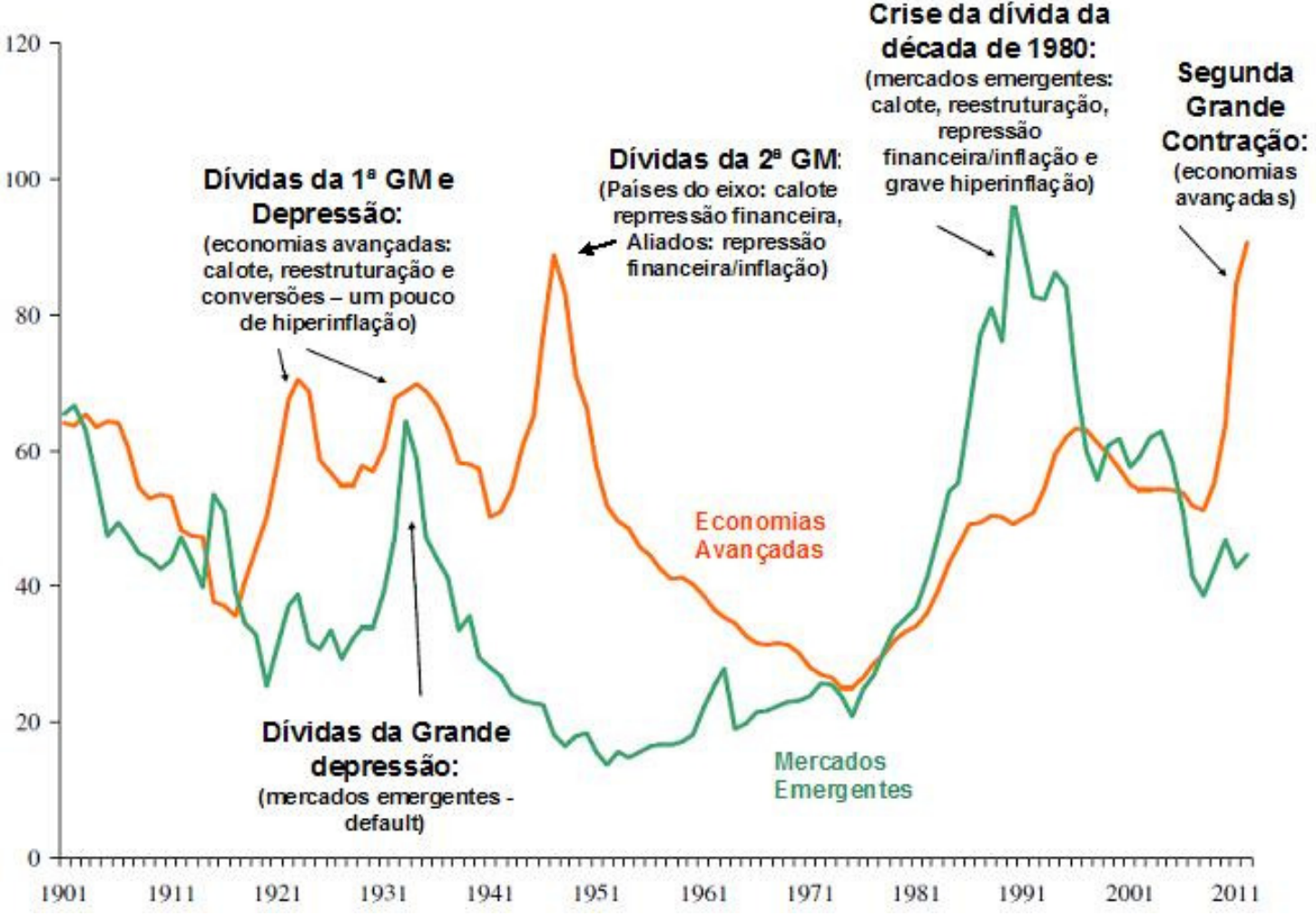

Fonte: Elaboração própria a partir de Reinhart e Sbrancia (2011).

A Figura 2 mostra o aumento da dívida pública real nos três anos seguintes às graves crises bancárias do século XX. $\mathrm{O}$ acúmulo da dívida pública tem sido uma característica definidora do rescaldo das crises bancárias por mais de um século, com as finanças do governo se deteriorando, em média, em 86\%. Mais amplamente, um exame das consequências da gravidade da crise financeira mostra efeitos profundos e duradouros sobre os preços de ativos, produção e emprego. $\mathrm{O}$ desemprego sobe e as quedas de preços dos imóveis se estendem por vários anos (REINHART; ROGOFF, 2010). 
Figura 2 - Dívida acumulada pelo setor público nos três anos seguintes às crises bancárias

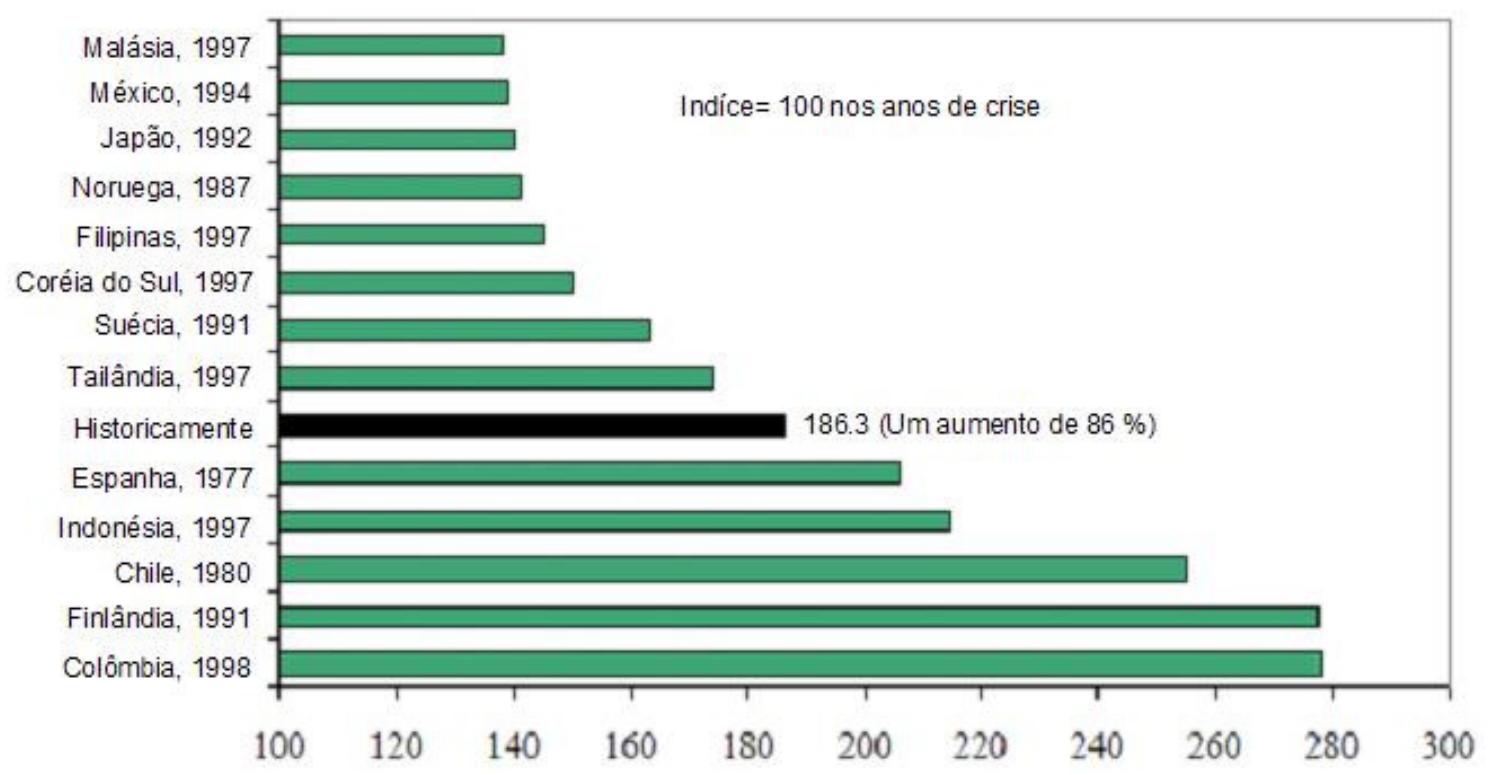

Fonte: Elaboração própria a partir de Reinhart e Rogoff (2011).

Em uma análise complementar de episódios de desalavancagem de dívida privada seguidas de crises financeiras sistêmicas, Reinhart e Reinhart (2010) mostram que o processo de redução da dívida continua em média por cerca de sete anos. Além disso, devido à queda na produção e aos atrasos acumulados sobre dívidas existentes, o nível da dívida privada em geral continua a subir até mesmo dois ou três anos, mesmo após o auge da crise financeira, retardando a redução efetiva do nível da dívida. A combinação de alta e escalada da dívida pública e o processo prolongado de desalavancagem privada faz com que os próximos 10 anos a partir de 2008 sejam descritos como a década da dívida (REINHART; REINHART, 2010).

Se as taxas de juros reais permanecerem muito baixas por um longo período, carregando os custos da dívida, esta será correspondentemente baixa, e índices de alavancagem excepcionalmente altos podem persistir mais do que o tempo habitual. Historicamente, episódios de alta alavancagem têm sido associados a crescimento econômico mais lento. Essa observação aplica-se aos episódios de alta da dívida que se seguem na esteira de guerras, bem como aos seus homólogos tempos de paz. Também caracteriza episódios em que elevados níveis de endividamento não foram associados a taxas de juros significativamente mais elevadas (REINHART; REINHART, 2010).

Através de uma robusta base de dados, Qian et al. (2010) chegam a uma linha do tempo das crises, da dívida externa, bancárias e inflacionárias (Figura 3). Analisando países de alta renda (avançados) e de média e baixa renda (emergentes), os autores chegam à conclusão de que países emergentes foram histori- 
camente mais vulneráveis a crises externas, diferem pouco dos países avançados em termos de crises inflacionárias e têm poucas diferenças em relação a crises bancárias. Isto é, as crises bancárias parecem ser as que mais exigem novas abordagens por parte dos países, uma vez que não têm sido solucionadas de modo adequado pela economia global, afetando todos de maneira quase uniforme. Isso fica evidente nos resultados de Reinhart e Rogoff (2008), que identificaram apenas uma crise bancária, de 1947 a 1975, e 31, de 1976 a 2008, o que Bresser-Pereira (2010) denota como um contraste entre a estabilidade da era de Bretton Wood e a instabilidade posterior à liberalização financeira.

Figura 3 - Linha do tempo das crises de 1550-2010

\begin{tabular}{|c|c|c|c|}
\hline & Crises de dívida externa & Crises bancárias & Crises inflacionárias \\
\hline 1550 & \multirow{2}{*}{$\begin{array}{l}\text { Frequente em economias } \\
\text { avançadas (incluindo as } \\
\text { potências do periodo). } \\
\text { Periódicas em alguns casos. }\end{array}$} & \multirow{2}{*}{ Raras } & \multirow{4}{*}{ Raras } \\
\hline $\begin{array}{r}\text { Fim das guerras } \\
\text { Napoleônicas } \\
1815\end{array}$ & & & \\
\hline $\begin{array}{r}1826 \\
1850\end{array}$ & \multirow{5}{*}{$\begin{array}{l}\text { Frequente em economias } \\
\text { avançadas periféricas e em } \\
\text { maior número em países } \\
\text { emergentes }\end{array}$} & $\begin{array}{c}\text { Periódicas em países } \\
\text { avançados / Raras em } \\
\text { emergentes }\end{array}$ & \\
\hline 1900 & & Periódicas em países & \\
\hline Início da $1^{\mathrm{a}} \mathrm{GM} 1913$ & & em emergentes & \multirow{2}{*}{$\begin{array}{c}\text { Frequente em países } \\
\text { avançados e emergentes }\end{array}$} \\
\hline Fim da $2^{\mathrm{a}}$ GM 1945 & & \multirow[b]{2}{*}{$\begin{array}{c}\text { Raras em países avançados e } \\
\text { emergentes }\end{array}$} & \\
\hline $\begin{array}{r}\text { Pós- } 1945 \\
1964\end{array}$ & & & Raras \\
\hline $\begin{array}{r}1973 \\
1980\end{array}$ & \multirow{4}{*}{$\begin{array}{l}\text { Periódicas em alguns mercados } \\
\text { emergentes }\end{array}$} & \multirow{4}{*}{$\begin{array}{c}\text { Mais frequente em países } \\
\text { avançados / Periódicos em } \\
\text { emergentes }\end{array}$} & $\begin{array}{c}\text { Frequente em países } \\
\text { avançados e emergentes }\end{array}$ \\
\hline Início dos anos 1990 & & & Frequente em emergentes \\
\hline 2000 & & & \\
\hline 2009 & & & Raras \\
\hline 2010 & $? ? ?$ & & \\
\hline
\end{tabular}

Fonte: Elaboração própria a partir de Qian et al. (2010).

\subsection{A Dívida Adquirida}

A Figura 4 ilustra o aumento da dívida pública (ajustada pela inflação) que ocorreu desde 2007. Para países com crises financeiras sistêmicas e/ou com problemas de dívida (Grécia, Islândia, Portugal, Espanha, Reino Unido e Estados Unidos), os níveis de dívida aumentaram em cerca de $134 \%$, superando por uma margem considerável o valor de $86 \%$ que Reinhart e Rogoff (2010) encontraram. Mesmo em países que não experimentaram uma grande crise financeira, a dívida pública aumentou em média 36\% em termos reais. Muitas economias adotaram pacotes de estímulo para lidar com a recessão global e foram atingidas por quedas marcantes de receitas do governo. Além disso, alguns dos maiores aumentos nas 
cargas da dívida dos países que não sofreram crise (como Noruega, Austrália e Chile) referem-se à reversão cíclica dos preços mundiais de commodities que acompanharam a recessão global.

Figura 4 - Aumento da dívida pública real acumulada desde 2007: em países selecionados

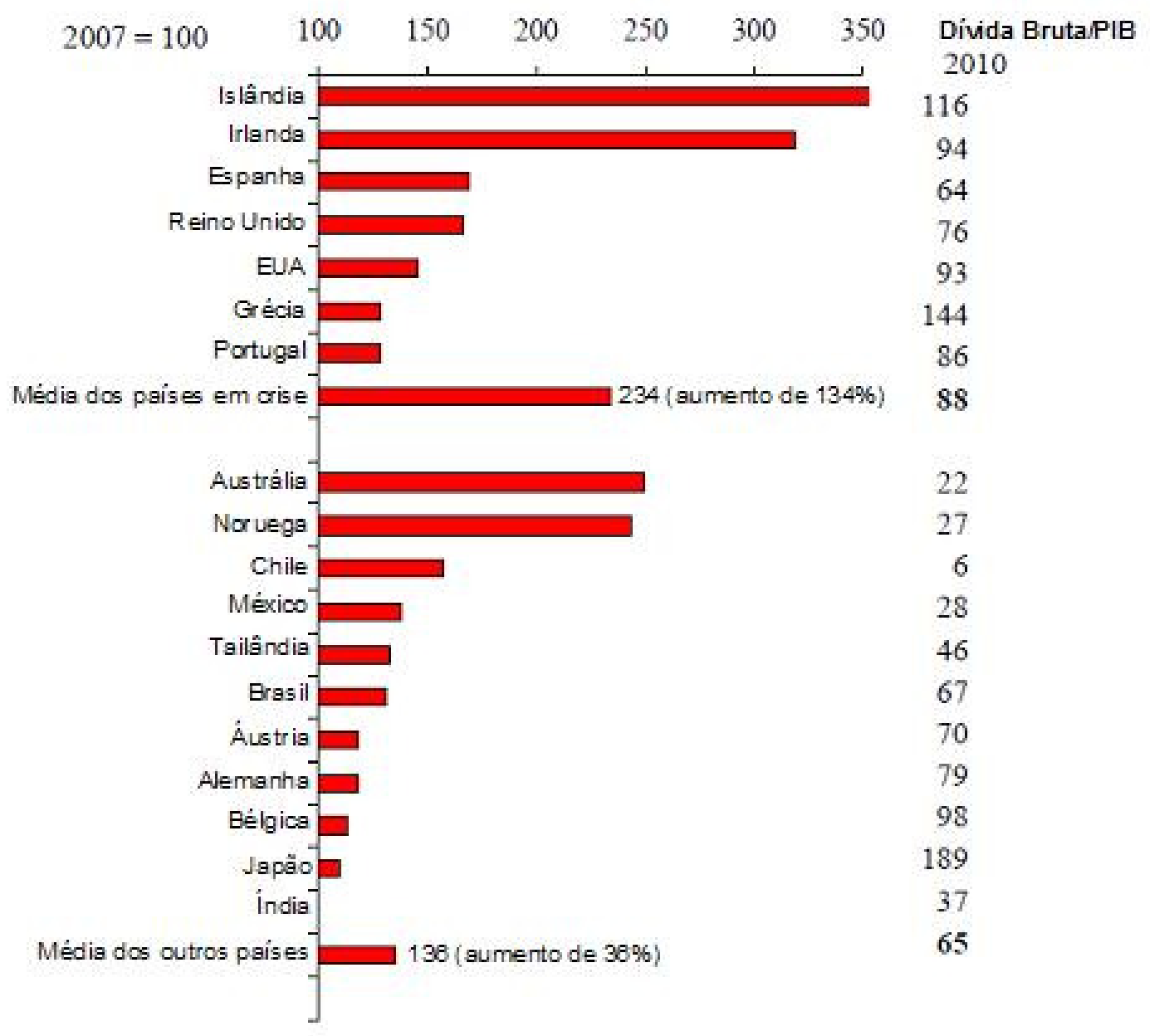

Fonte: Reinhart e Rogoff (2011).

Com a eclosão da crise de 2007, medidas governamentais de provimento de liquidez e de capital aos bancos com grande exposição nos seus balanços transformaram passivos privados em débitos públicos. Alguns bancos centrais absorveram ativos privados em seus balanços, enquanto os tesouros se incumbiam de emitir títulos públicos a fim de sustentar a carteira desses bancos (BELLUZZO, 2011). Essa aquisição de ativos tóxicos por parte dos governos e a deterioração de seu quadro fiscal teve efeitos alarmantes, principalmente em países com posições de dívida comprometidas, como foram os casos da Grécia, Irlanda, Portugal, Espanha e Itália. Em relação a esses países, ela acentuou o recente problema de dívida soberana. Essas nações mostraram as assimetrias existentes dentro do bloco 
europeu e sofreram ataques especulativos, colocando em dúvida a sustentabilidade de suas dívidas públicas.

Atualmente, é nítida a preocupação de que a crise na economia mundial se intensifique pelo temor engendrado na zona do euro, tendo a Grécia como principal expoente. O país acumulou uma dívida de cerca de 300 bilhões de euros e um déficit fiscal, em 2009, de 13\%, bem acima do teto fixado pelo Tratado de Maastricht, que estipula 3\% do PIB. ${ }^{5}$ Eichengreen et al.(2011) relatam que não faz parte da tradição europeia manter baixas taxas de dívida pública, com exceção de apenas alguns países que foram capazes de superar suas dívidas como resultado de seus respectivos processos de catching-up. Os países da zona do euro, em média, foram capazes de gerir sua dívida pública como proporção do PIB estabilizada somente nos primeiros dez anos da moeda única. Na época pré-crise, 17 membros da zona do euro já possuíam uma dívida pública em relação ao PIB superior a $60 \%$ em 2006. Três países, Grécia, Itália e Bélgica, possuíam uma relação dívida/PIB de $90 \%$. A Espanha não alcançou esses níveis, mas surpreende o fato de que logrou uma redução, entre 2004 e 2007, de 48\% para 38\% da relação dívida/PIB, diferentemente dos demais PIIGS, porém, após 2007, alcançava um déficit de quase $12 \%$ do PIB, em 2009, e o patamar da relação dívida/PIB era da ordem de $70 \%$ em 2010 (OREIRO, 2011). Essas dívidas não foram oriundas de guerras ou catástrofes naturais, mas uma maneira de oferecer cada vez mais serviços públicos e realizar transferências. Na Alemanha, por exemplo, as transferências e subsídios aumentaram em 9,5 pontos percentuais do PIB entre 1970 e 1995, enquanto as receitas totais aumentaram apenas 6,1 pontos percentuais. Na Holanda, esses números atingiram 7,1 e 5,6, respectivamente (EICHENGREEN et al., 2011).

Conforme a taxonomia minskyana, pode-se afirmar que a Grécia, como alguns outros países europeus, está em situação Ponzi - em que os recursos provenientes de seus ativos não são suficientes para cumprir suas obrigações financeiras e, em razão disso, requer-se um endividamento crescente. Essa situação se agrava em períodos de crise em que os empréstimos interbancários são limitados e o financiamento, de modo geral, se estanca. A Figura 5 mostra o descolamento da Grécia em relação aos títulos alemães, mostrando a nítida reavaliação dos investidores acerca das posições dos títulos gregos. Somam-se a isso as seguidas rodadas de rebaixamento de rating de dívida soberana de alguns países, que acentuaram a incerteza dos investidores.

5 Atualmente, o déficit fiscal grego situa-se entre 6\% e 9\%, segundo The Economist (2011a, 2011b). 
Figura 5 - Spreads dos títulos soberanos sobre os títulos alemães (pontos bases): países selecionados

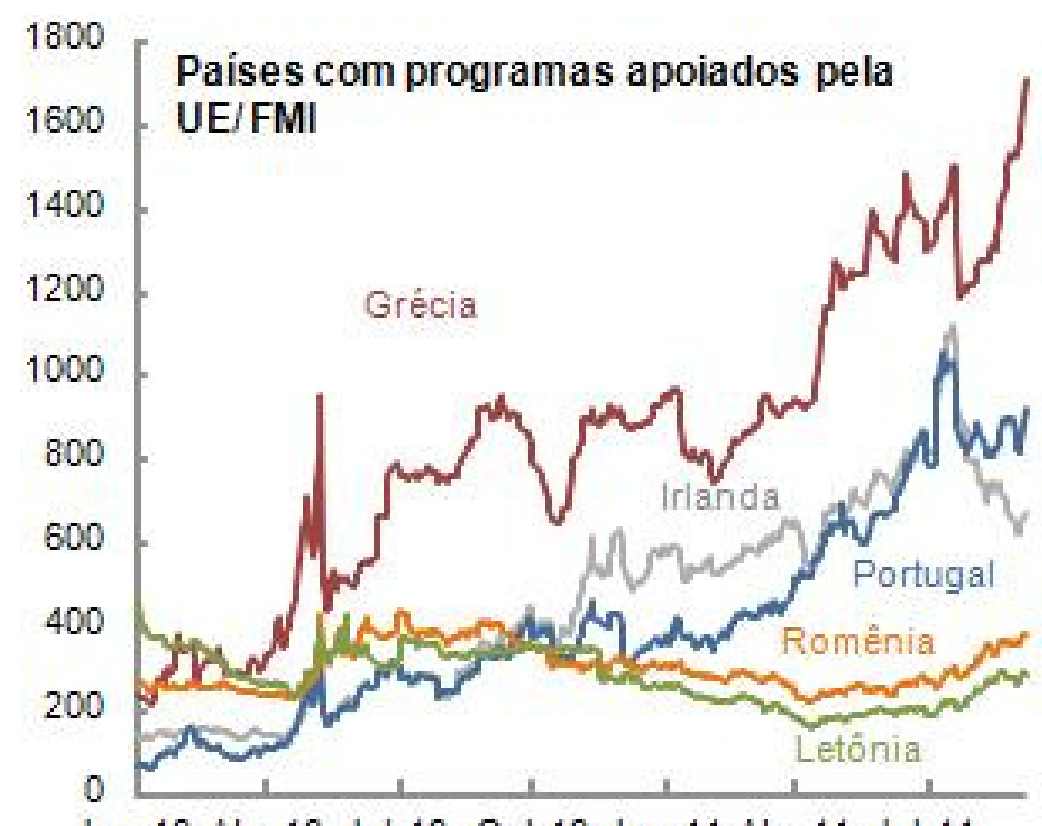

Jan-10 Abr-10 Jul-10 Out-10 Jan-11 Abr-11 Jul-11

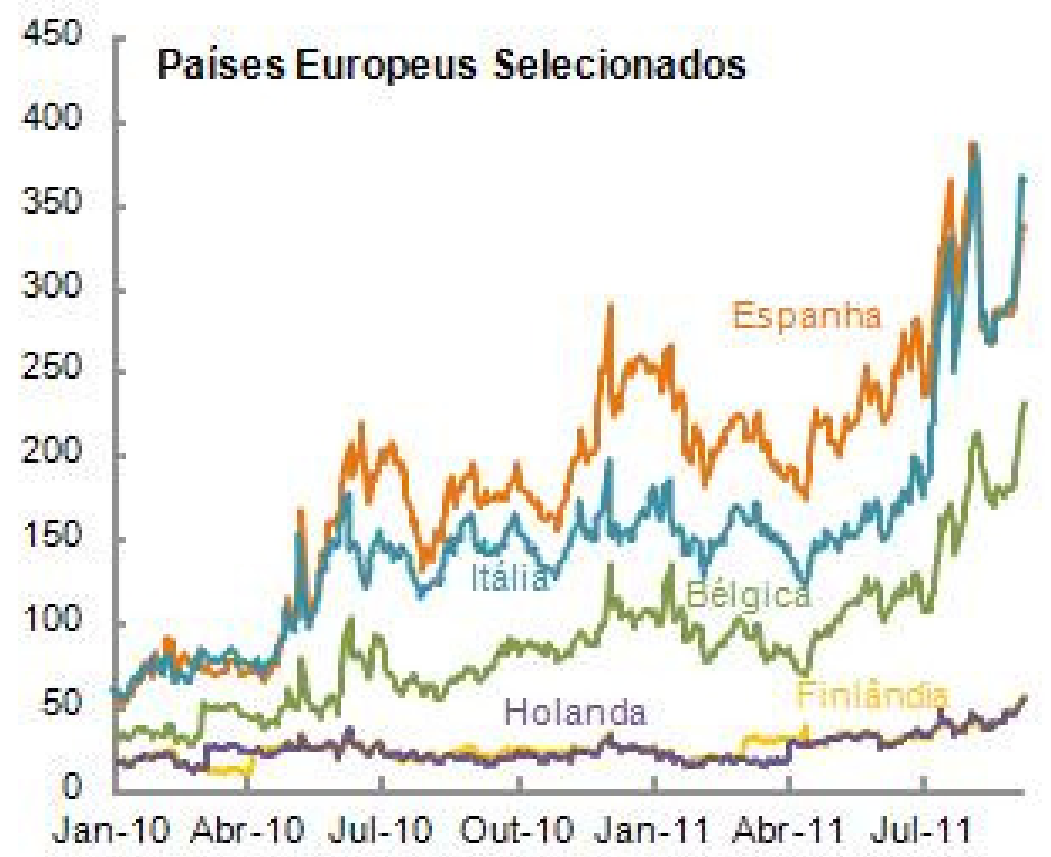

Fonte: Fundo Monetário Internacional - FMI (2011).

É possível notar na Figura 6 mudanças na dívida bruta dos países avançados que incorreram em déficits fiscais sucessivos desde o início da crise de 2007, a fim de mitigar as perturbações econômicas e sociais decorrentes do período de turbulência. A dívida pública grega em relação ao PIB teve um aumento, na sua já elevada dívida, de cerca de 105\% como proporção do PIB, em 2007, para estimados 166\% em 2011 (FMI, 2011). A Irlanda sofreu um expressivo aumento em sua dívida pública/ 
PIB de 25\%, em 2007, para estimados 109\% em 2011 (FMI, 2011). Um dos principais motivos foram seus sucessivos resultados primários, que passaram de um superávit de cerca de 4\% do PIB, em 2006, para um déficit de 29\% em 2010 (FMI, 2011).

Figura 6 - Economias avançadas selecionadas: dívida pública bruta

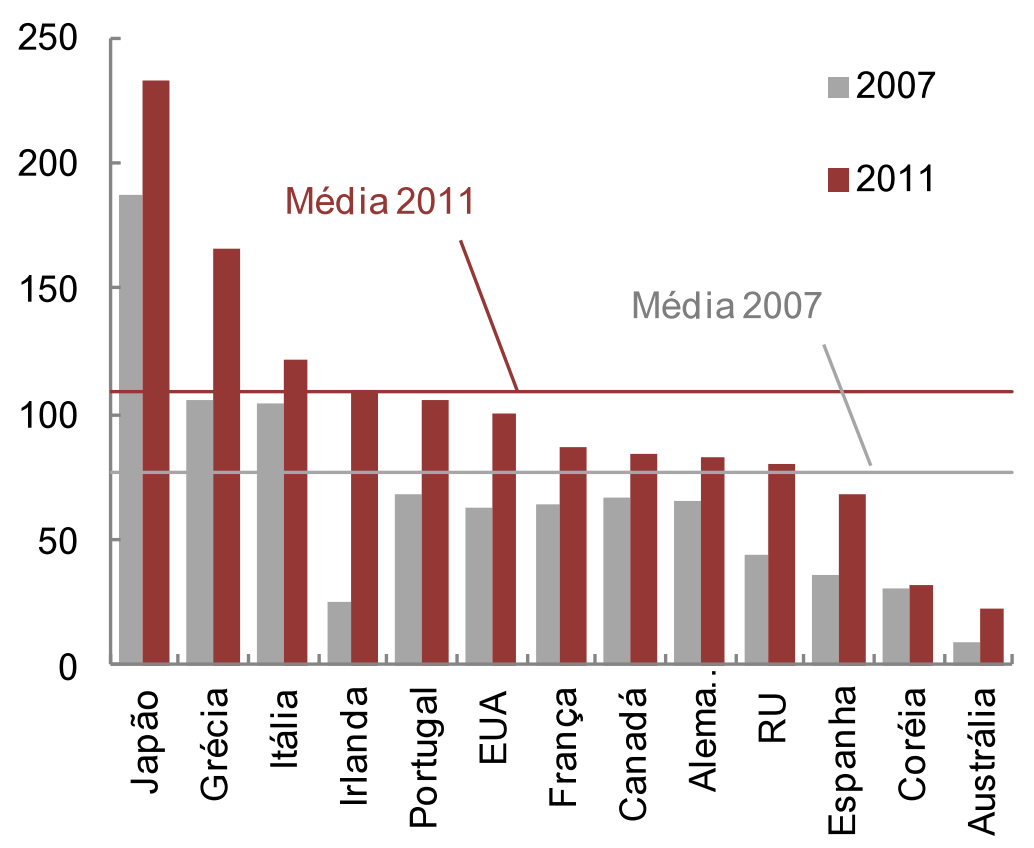

Fonte: FMI (2011).

A seguir, apresentamos uma discussão sobre a política fiscal e como deveria ser repensada, uma vez que se tornou um instrumento estabilizador crucial para superar a crise financeira de 2007 e intensificou, posteriormente, a crise fiscal de alguns países.

\section{Repensando a Política Fiscal}

Para fazer frente à crise financeira internacional, os governos desenvolveram enormes pacotes de estímulo fiscal, apoiados por governos e empresas. Feldstein (2009a) discute esse fato, tratando-o como uma mudança de consenso que outrora havia se estabelecido em Economia de que a política fiscal seria pouco útil como instrumento anticíclico. Para o autor, análises empíricas das experiências de políticas fiscais pós-Grande Depressão dos anos 1930 levantaram dúvidas com relação a sua eficácia. O aumento simultâneo da inflação e do desemprego na década de 1960 deixava claro, segundo ele, que a estratégia fiscal não estaria desempenhando satisfatoriamente seu papel, o que ocasionou uma mudança de foco para a política monetária. A baixa taxa de inflação desde 1980 e a diminuição da volatilidade cíclica reforçaram o consenso em torno da suposta eficácia da política monetária. 
O interesse no estímulo fiscal recente se deve ao fato de que a política monetária não seria eficaz em levar a economia ao pleno emprego, dada a natureza distinta da recessão deflagrada pela crise de 2008. As quedas contínuas no valor dos títulos lastreados por hipotecas e dos seus derivativos refletia o temor de um volume crescente de inadimplência, o que erodiu o capital das instituições financeiras, minando sua disposição em ofertar crédito. $\mathrm{O}$ resultado foi um mercado disfuncional que não fornecia crédito ou não respondia às mudanças nas taxas de juros.

Segundo o autor, até o final de 2007, por conta da incapacidade do FED em evitar uma recessão, os economistas passaram a defender um maior estímulo fiscal. A desoneração tributária temporária era vista como algo que poderia obter apoio bipartidário e seria implementado rapidamente. O congresso se apressou em aprovar uma redução de impostos de US $\$ 80$ bilhões e já haveria renda disponível na mão dos contribuintes em maio e junho de 2008. No entanto, os gastos dos consumidores responderam muito fracamente. Além disso, o FED e o tesouro tomaram uma série de medidas para ajudar os mercados de crédito, o que evitou um colapso ainda maior e gerou disponibilidade de crédito em bancos, fundos mútuos do mercado monetário e na capacidade das empresas em emitir títulos. Essas medidas não tiveram sucesso também, uma vez que não expandiram o crédito total nem lidaram com o problema fundamental de um mercado disfuncional. Nesse ponto, o autor conclui que o mercado de crédito, embora seja necessário para o crescimento sustentado de longo prazo, não estava sendo suficiente para reverter a espiral descendente da demanda agregada.

Esses fatores somados levaram à percepção da necessidade de um grande pacote fiscal. Isso porque o declínio da demanda era diferente dos típicos ciclos econômicos do passado, em que a demanda se recupera com os estoques e a capacidade produtiva em excesso é absorvida. O desafio, segundo estimativas do autor, era aumentar os gastos domésticos em cerca de US $\$ 400$ bilhões por ano em 2009 e 2010. Outro ponto ressaltado era quanto ao dólar mais competitivo: a conclusão seria que poderia ser apenas suficiente para compensar a queda na demanda de exportação que resultaria da redução do nível de renda dos estrangeiros. Assim, caberia à política fiscal apoiar o aumento da despesa agregada. ${ }^{6}$

Romer (2011) compartilha com a nova percepção quanto à retomada da política fiscal como um importante instrumento de estabilização. Segundo ele, a crise financeira acabou com algumas noções consensuais da sabedoria convencional quanto à formulação da política macroeconômica. Entre elas, temos: que as flutuações macroeconômicas estão sob controle; que questões de regulação financeira são desnecessárias; e que o cavalo de batalha novo keynesiano, o modelo de

$6 \quad$ Feldstein (2009b) critica o estímulo de US $\$ 800$ bilhões dado pelo presidente Obama, pois, entre outros motivos, o programa de gastos engendrado pelo governo cria dinâmicas políticas que tornam difícil terminá-lo. 
equilíbrio geral dinâmico estocástico (DSGE), sobre o qual os macroeconomistas concentram muito da sua atenção, tem sido de mínimo valor para enfrentar a maior crise macroeconômica desde a crise de 1929. A partir disso, o autor lista quatro lições de política fiscal a partir da crise financeira de 2007:

a) precisamos de instrumentos fiscais para a estabilização de curto prazo. Antes havia amplo acordo entre os macroeconomistas e os políticos de que a estabilização de curto prazo era função apenas da política monetária, pois é mais isolada de pressões políticas e pode facilmente ser colocada na mão de especialistas independentes;

b) temos evidências ainda mais fortes de que a política fiscal é eficaz mais do que tínhamos antes da crise;

c) o espaço de manobra fiscal é valioso. Estar em uma situação fiscal saudável é muito importante para responder de forma agressiva a um colapso de demanda agregada;

d) considerações de economia política são cruciais.

A partir das lições expostas, Romer (2011) afirma que as perspectivas para os próximos anos não são boas, uma vez que a política fiscal, até então adormecida, foi feita de forma reativa e pouco ordenada. Para ele, uma maior avaliação do que deve ser feito é necessário quanto à política fiscal, a fim de assegurar sua transparência. Nas economias avançadas, o uso criativo da política monetária deve ser mais agressivo e deve ser dado maior estímulo fiscal de curto prazo e promulgação de medidas para resolver os problemas fiscais de longo prazo. Neste, ainda deve haver regulação. A crise agravou os problemas fiscais de longo prazo, o que reduziu o espaço fiscal disponível em uma eventual crise futura e aumentou as chances de que novas crises possam começar por conta da perda de confiança na solidez fiscal dos países.

Para Eichengreen (2010), a resposta política foi rápida e poderosa: países avançados responderam com flexibilização da política monetária e fiscal agressiva. Os países emergentes, graças a suas posições fiscais fortes, puderam aumentar a despesa pública sem medo de prejudicar a sustentabilidade fiscal. As reservas internacionais foram outro mecanismo para evitar desequilíbrios na taxa de câmbio e, quando necessário, usado para suprir o financiamento de dólares necessários pelos investidores. Segundo seus dados, os Estados Unidos se adiantaram aplicando o maior estímulo de qualquer país, o que é evidente, dado que era o epicentro da crise. Até 2009, no entanto, o estímulo dos mercados emergentes do G20 se igualou aos Estados Unidos como proporção do PIB.

Com o passar do tempo, as medidas de estímulos para evitar a "Grande Depressão 2.0" começaram a não ser olhadas de forma tão positiva, acarretando 
o ressurgimento da volatilidade financeira na Europa em 2010 e o contágio para outros países, juntamente com a redução fiscal drástica que reduziu as parcerias público-privadas de estímulo à demanda agregada. Os policy makers evitaram uma maior queda na demanda agregada em 2007-2009 ao custo de um maior colapso no futuro, quando os investidores despertaram para os problemas de sustentabilidade da dívida soberana, forçando uma redução fiscal de despesas pelos agora governos perigosamente endividados. Eles socializaram as dívidas podres do sistema financeiro e não financeiro, transformando um problema que antes era de dívida privada em um problema de sustentabilidade da dívida pública. Embora reconheça o papel da facilidade de ser crítico com o benefício da retrospectiva, Eichengreen (2010) destaca algumas hipóteses para o que poderia ter sido feito diferente:

a) os governos deveriam ter sido mais conscientes do potencial problema de sustentabilidade da dívida pública e exercido maior controle na aplicação do estímulo fiscal. Nos Estados Unidos, não há sinais de que o estímulo de 787 bilhões de dólares foi grande, pois substituiu, no máximo, um terço dos gastos privados vaporizados na crise. Esse estímulo também não foi suficiente para impedir que a taxa de desemprego aumentasse para dois dígitos. Não houve pressão de alta sobre os rendimentos do tesouro: em meados de maio de 2010, os títulos de dez anos renderam $3,14 \%$ ao ano, pouco abaixo do rendimento de 3,17\% do ano anterior (EICHENGREEN, 2010, p. 11-12). Isso tudo sugere que se houvesse o conhecimento que se tem agora ou, alternativamente, na ausência de restrições políticas, estímulos fiscais maiores poderiam ter sido melhores;

b) a segunda hipótese é que a resposta fiscal deveria ter sido mais exigente. Países que entraram na crise com cargas pesadas de dívida deveriam ter sido mais cautelosos antes de empreenderem déficits adicionais. Deveriam estar atentos a dois problemas, ao da sustentabilidade da dívida que havia sido herdada e ao fato de que a relação dívida/PIB cresceria mais rapidamente, devido ao dano permanente em suas economias e sistemas financeiros. Para evitar um enfraquecimento do crescimento global, os menores déficits em países endividados deveriam ter sido seguidos por maiores gastos de outros países em melhor posição de empreendê-los. Uma coordenação internacional adicional teria sido necessária, em outras palavras. A chamada para o estímulo fiscal foi coordenada pelo G20 com comunicados regulares, porém o tamanho dos pacotes de estímulos nacionais era, ao final, deixado às autoridades nacionais; 
c) as autoridades fiscais deveriam ter detalhado suas estratégias de saída. Deveriam explicar e tornar crível que os estímulos eram passageiros até a retomada oportuna da confiança, incentivando os gastos da economia privada, e reduzir a magnitude do déficit que as autoridades fiscais tiveram de produzir. Menos déficit no futuro significaria juros mais baixos no futuro, que teria significado menores taxas de juros agora, que encorajariam o investimento privado. Certamente que, na medida em que as taxas de juros estivessem próximas de zero, esse mecanismo teria ajudado menos. Mas ainda se pode imaginar que os planos críveis para eliminação dos déficits excepcionais reforçariam a confiança e os gastos privados, permitindo um gasto maior por parte das autoridades fiscais;

d) os governos fizeram muito pouco para reestruturar e capitalizar os sistemas bancários, permitindo que os problemas da dívida soberana e privada pudessem pôr em perigo a estabilidade dos sistemas financeiros. Se alguma coisa sabemos sobre crises bancárias é que quanto mais tempo a sua resolução demora, mais cara se torna;

e) por último, os países deveriam ter confiado mais na flexibilização da política monetária e fiscal mais frouxa. Ao contrário do FED e do Banco da Inglaterra, o banco central europeu estava relutante em empurrar as taxas de juros para perto de zero e se envolver em uma flexibilização quantitativa, argumentando que a taxa de juros deveria se manter em território positivo, para que ainda tivesse espaço para reduzi-la se as condições se deteriorassem ainda mais.

\section{Considerações Finais}

As perspectivas futuras da economia mundial parecem sombrias se acompanharmos os recentes desdobramentos da atual crise europeia. Aumentos nos déficits de países já endividados e a incerteza relativa à recuperação econômica têm provocado novas rodadas de crise econômica e política, assim como também cresce cada vez mais o risco de contágio. Procuramos mostrar a atualidade da discussão das políticas fiscais e as suas implicações. Tanto a história quanto o período recente mostram que as políticas fiscais são reativas à crise. Concluímos, a partir dos estudos e dados coletados, que todo o circuito "dívida bancária - política fiscal - incerteza - dívida soberana" é algo que só pode ser evitado ex ante. Nesse caso, a regulação do sistema financeiro é um clichê recorrente. Autores renomados têm dúvidas sobre o futuro da economia, e os modelos convencionais, com os quais nos acostumamos a lidar em períodos de aparente estabilidade econô- 
mica, não dão conta de prognosticar o futuro da economia. A adoção, vista por muitos como equivocada, de políticas fiscais desordenadas e que só agravaram problemas de dívida soberana tornam as perspectivas futuras não animadoras, uma vez que poderemos vivenciar um período de baixo crescimento econômico mundial. Embora seja plausível supor que países emergentes serão capazes de sustentar algum crescimento com sua vigorosa classe média em ascensão, desdobramentos favoráveis no epicentro da crise de dívidas soberanas serão fundamentais para reverter perspectivas pouco otimistas, dado o importante papel desempenhado pelos países da zona do euro na economia global.

\section{Referências}

ALESINA, A. F.; ARDAGNA, S. Large changes in fiscal policy: taxes versus spending. NBER Working Paper Series, Cambridge, US, n. 15438, Oct. 2009.

ARESTIS, P.; SAWYER, M. The return of fiscal policy. Journal of Post Keynesian Economics, Armonk, US, v. 32, n. 3, p. 327-346, Spring 2010.

AUERBACH, A.; GALE, W. G.; HARRIS, B. H. Activist fiscal policy. The Journal of Economic Perspectives, Nashville, v. 24, n. 4, p. 141-164, Fall 2010.

BANK FOR INTERNATIONAL SETTLEMENTS - BIS. 79th annual report. 2009. Disponível em: < http://www.bis.org/publ/arpdf/ar2009e.htm>. Acesso em: 10 set. 2011.

BELLUZZO, L. G. Crise europeia. Valor Econômico, São Paulo, 01/02/2011.

BRAINARD, W. C. Uncertainty and the effectiveness of policy. American Economic Review, Nashville, US, v. 57, n. 2, p. 411-25, 1967.

BRESSER-PEREIRA, L. C. A crise financeira de 2008. Revista de Economia Política, São Paulo, V. 29, n.1, p. 133-149, jan./mar. 2009.

n. 86, mar. 2010.

A crise financeira global e depois: um novo capitalismo?". Novos Estudos CEBRAP,

CARVALHO, F. J. A crise econômica internacional em 2010: uma avaliação a meio do caminho. Revista de Economia Política, São Paulo, v. 31, n. 2, p. 315-335, abr./jun. 2011.

EICHENGREEN, B. Macroeconomic and financial policies before and after the crisis. In: OBSTFELD, M.; CHO, D.; MASON, A. (Ed.). Global Economic Crisis. Cheltenham: Edward Elgar, 2010.

EICHENGREEN, B. et al. Public debts: nuts, bolts and worries. Geneva: International Center for Monetary and Banking Studies, 2011. (Geneva Reports on the World Economy, n. 13).

EUROPEAN economies: Europe's deepening crises. The Economist, London, 12 Jan. $2011 \mathrm{~b}$.

FARHI, M. et al. A crise e os desafios para a nova arquitetura financeira internacional. Revista de Economia Política, São Paulo, v. 29, n.1, p. 133-149, jan./mar. 2009.

FELDSTEIN, M. Rethinking the role of fiscal policy. NBER Working Paper Series, Cambridge, US, n. 14684, p. 1-11, Jan. 2009.

An $\$ 800$ billion mistake. The Washington Post, 29/jan/2009b. 
FERRARI FILHO, F.; PAULA, L. F. A crise das finanças desregulamentadas: o que fazer? Revista de Economia Política, São Paulo, v. 29, n.1, p. 142-144, jan./mar. 2009.

FUNDO MONETÁRIO INTERNACIONAL - FMI. Fiscal Monitor: Adressing fiscal challenges to reduce economic risks. 2011. Disponivel em: < http://www.imf.org/external/pubs/ft/fm/2011/02/ fmindex.htm >. Acesso em: 27 set. 2011.

GREECE'S economic woes: The labours of austerity. The Economist, London, 07 Abr. $2011 \mathrm{a}$.

HERMAN, J. Da liberalização à crise financeira norte-americana: a morte anunciada chega ao Paraíso. Revista de Economia Política, São Paulo, v. 29, n.1, p. 138-141, jan./mar. 2009.

HOLLAND, M.; MORI, R. Respostas à crise financeira de 2008 de uma perspectiva brasileira. São Paulo: FGV, 2010. (Textos para Discussão, n. 249).

LUCAS, R. E., JR. Econometric policy evaluation: A critique. Carnegie-Rochester Conference Series on Public Policy, Amsterdam, v. 1, n. 1, p. 19-46, Jan. 1976.

MENDONÇA, A. R. R. Regulamentação bancária, gestão de riscos e gestação da desordem financeira. Revista de Economia Política, São Paulo, v. 29, n.1, p. 141-142, jan./mar. 2009.

MISHKIN, F. Over the cliff: from the subprime to the global financial crisis. NBER Working Paper Series, Cambridge, US, n. 16609, p. 1-28, Dec. 2010.

OREIRO, J. L. A crise na Europa e os dilemas da Espanha. Revista de Economia Política, São Paulo, v. 31, n. 2, p. 326-328, abr.jun. 2011.

QIAN, R.; REINHART, C.; ROGOFF, K. On graduation from default, inflation and banking crisis: elusive or illusion? NBER Working Paper Series, Cambridge, US, n. 16618, p. 1-57, Jul. 2010.

PAULA, L. F.; FERRARI FILHO, F. Tempos keynesianos. Revista de Economia Política, São Paulo, v. 31, n. 2, p. 315-317, abr.jun. 2011.

PRATES, D. M. O efeito-contágio da crise global sobre os países emergentes. Revista de Economia Política, São Paulo, v. 31, n. 2, p. 328-330, abr.jun. 2011.

REINHART, C.; REINHART, V. After the fall. Federal Reserve Bank of Kansas City Economic Symposium, Macroeconomic Challenges: The Decade Ahead, manuscript. 2010. Disponível em: < http://www.kansascityfed.org/publicat/sympos/2010/reinhart-paper.pdf. > . Acesso em: 20 mar. 2012.

REINHART, C.; ROGOFF, K. Banking crises: an equal opportunity menace. NBER Working Paper Series, Cambridge, US, n. 14587, Dec. 2008.

Oito séculos de delírios financeiros. Rio de Janeiro: Elsevier, 2010.

. A decade of debt”. Discussion Paper Series, London, n. 8310, p. 1- 48, Apr. 2011.

REINHART, C.; SBRANCIA, M. B. The liquidation of government debt. NBER Working Paper Series, n. 16893. 2011.

ROMER, D. What have we learned about fiscal policy from the crisis. IMF Conference on Macro and Growth Policies in the Wake of the Crisis, Washington, US, p. 1-12, Mar. 2011.

SICSÚ, J. Para além das políticas de resgate. Revista de Economia Política, São Paulo, v. 29, n.1, p. 133-149, jan./mar. 2009.

Recebido em: 01/04/2012.

Aceito em: 26/06/2012. 